\title{
A PARTICIPAÇÃO DE ESTUDANTES UNIVERSITÁRIOS NO TRABALHO PRODUTIVO E REPRODUTIVO'
}

\author{
TANIA LUDMILA DIAS TOSTA
}

\section{RESUMO}

0 presente trabalho discute a articulação entre estudo, trabalho e família para estudantes de ensino superior a partir dos resultados de uma pesquisa mais ampla realizada na Universidade Federal de Goiás. Tomando como base uma amostra de 527 estudantes, busca-se caracterizá-los de acordo com seus pertencimentos e posições sociais, além de compreender os usos do tempo e a participação de homens e mulheres no trabalho produtivo e reprodutivo. A análise indica que, apesar de jovens mulheres constituírem a maioria da população universitária, as construções hierárquicas das relações de gênero persistem e a responsabilidade pelos afazeres domésticos ainda é assumida, de forma preponderante, como feminina.

ENSINO SUPERIOR • RELAÇÕES DE GÊNERO • TRABALHO • FAMÍLIAS

\section{THE PARTICIPATION OF UNIVERSITY STUDENTS IN PRODUCTIVE AND REPRODUCTIVE WORK}

\section{ABSTRACT}

This paper discusses the links among study, work and family for higher education students based on the results of a broader research carried out at the Universidade Federal de Goiás (BR). Based on a sample of 527 students, this work seeks to characterize them according to their sense of belonging and social positions, their use of time and, also, the participation of men and women in productive and reproductive work. The analysis indicates that although young women make up the majority of the population, the hierarchical structures of gender relations persist and the responsibility for domestic work is still overwhelmingly assumed by women.
Uma primeira versão deste trabalho foi apresentada no IV Simpósio Internacional de Ciências Sociais da Faculdade de Ciências Sociais da Universidade Federal de Goiás, realizado em Goiânia de 11 a 14 de novembro de 2015 . 


\section{LA PARTICIPATION DES ÉTUDIANTS UNIVERSITAIRES DANS LE TRAVAIL PRODUCTIF ET REPRODUCTIF}

RÉSUMÉ

Ce travail discute l'articulation entre études, travail et famille pour des étudiants de niveau supérieur et utilise des résultats d'une recherche plus vaste menée à l'Universidade Federal de Goiás. En prenant comme base un échantillon de 527 étudiants, nous avons cherché à les caractériser en fonction de leur appartenance et de leur position sociale. Nous avons, par ailleurs, tenté de comprendre comment ils utilisaient leur temps et quelle était la participation des hommes et des femmes dans le travail productif et reproductif. Cette anlyse indique que, même si les jeunes femmes constituent la majorité de la population universitaire, les constructions hiérarchiques des relations de genre persistent et que la responsabilité pour les tâches domestiques est fondamentalement perçue comme appartenant au domaine féminin.

ENSEIGNEMENT SUPÉRIEUR・RELATIONS DE GENRE・TRAVAIL・FAMILLE

\section{LA PARTICIPACIÓN DE ESTUDIANTES UNIVERSITARIOS EN EL TRABAJO PRODUCTIVO Y REPRODUCTIVO}

RESUMEN

El presente trabajo discute la articulación entre estudio, trabajo y familia para estudiantes de la educación superior a partir de los resultados de una investigación más amplia realizada en la Universidade Federal de Goiás. Tomando como base una muestra de 527 estudiantes, se busca caracterizarlos de acuerdo a sus pertenencias y posiciones sociales, además de comprender los usos del tiempo y la participación de hombres y mujeres en el trabajo productivo y reproductivo. El análisis indica que, a pesar de que las mujeres jóvenes constituyen la mayoría de la población universitaria, las construcciones jerárquicas de las relaciones de género persisten y la responsabilidad por las tareas domésticas todavía es considerada, de forma preponderante, como femenina. 

importante para o entendimento das sociedades modernas (GROPPO, 2000). De acordo com a concepção de Mannheim, o pertencimento geracional não se caracterizaria apenas pelo tempo cronológico compartilhado por pessoas nascidas em certa época; sua posição em comum advém da possibilidade de vivenciar as mesmas experiências e de processá-las de forma semelhante (MANNHEIM, 1980; WELLER, 2010). Independentemente de suas idades, um grupo de pessoas pode ser apontado como jovem por compartilhar um gradiente de valores em comum, tais como vestuários, tipos musicais e hábitos. Mannheim também aponta a juventude como elemento dinamizador da sociedade, que tende a protagonizar e ajustar-se às transformações sociais, por constituir um segmento ainda em formação, não completamente inserido na ordem social (BEZERRA et al., 2013; MANNHEIM, 1980). Essa leitura indica que a participação de jovens nos processos de transformação social depende muito das condições sociais de sua inserção. Podem ser revolucionários ou afiliar-se a movimentos conservadores. Pensando na Europa da década de 1930, tanto se engajaram em movimentos democráticos como em movimentos fascistas, como foi o caso da juventude nazista.

Assim, o uso do plural do termo - juventudes - alude à necessidade de indicar a diversidade de vivências possíveis da juventude de acordo com classe, gênero, sexualidade, raça, etnia, origem, entre outros 
marcadores sociais da diferença (CARMO, 2001; FRAGA; IULIANELLI, 2003). Se a categoria juventude importa como construção social, não deve apagar as identidades plurais que nela se inscrevem (ABRAMO, 1994), pois a experiência de um jovem negro da periferia não é a mesma de um jovem branco de alta renda (TAVARES, 2012; WELLER, 2011).

Este artigo parte de um segmento particular da categoria: estudantes de ensino superior. Mais especificamente, estudantes de uma universidade pública brasileira. Embora essa condição os aproxime, outros tantos pertencimentos os diferenciam. A juventude de uma universitária trabalhadora chefe de família é muito distinta da juventude de um universitário em dedicação integral aos estudos.

Com base em uma pesquisa realizada na Universidade Federal de Goiás ${ }^{2}$ - UFG -, esta reflexão centra-se nas diferenças de gênero para compreender como alunos e alunas dessa instituição articulam atividade remunerada, formação educacional e cuidados com a casa e família. Para isso, analisa a divisão sexual do trabalho e a partilha do trabalho reprodutivo entre estudantes que participam do mercado de trabalho remunerado, além de traçar um paralelo entre os dados da pesquisa e alguns indicadores do Instituto Brasileiro de Geografia e Estatística - IBGE - e do Instituto Nacional de Estudos e Pesquisas Educacionais Anísio Teixeira - Inep.

Embora o trabalho reprodutivo possa ser compreendido de forma mais ampla, como todos os tipos de trabalho e cuidados necessários para a manutenção da vida e reprodução das próximas gerações (DUFFY, 2007), este artigo parte de uma concepção de trabalho reprodutivo mais restrita, relacionada ao conjunto de tarefas executadas gratuitamente no contexto da família (FOUGEYROLLAS-SCHWEBEL, 2009). São, portanto, as atividades do trabalho doméstico não remunerado, como limpeza, preparação dos alimentos, cuidado de crianças, entre outras.

\section{ESTUDANTES DE ENSINO SUPERIOR: POSIÇÕES E PERTENCIMENTOS}

A pesquisa partiu de uma amostra representativa, estratificada proporcionalmente de acordo com as regionais da universidade (Goiânia, Goiás, Catalão e Jataí) e a categoria da população investigada (estudantes, docentes, técnico-administrativos/as e terceirizados/as). Ao total, foram 669 entrevistados/as, dentre os/as quais se contam 527 estudantes. Para fins deste artigo, serão contabilizadas apenas as respostas dos/as estudantes, segmento de maior peso da comunidade universitária.

Para localizar as alunas e os alunos entrevistadas/os de acordo com seus pertencimentos e posições sociais, delineiam-se algumas das características mais significativas da amostra de estudantes da UFG. Em primeiro lugar, as/os estudantes entrevistadas/os dividem-se em $292 \mathrm{mu}$ lheres e 235 homens. A proporção maior de mulheres (55,4\% para 44,6\%)

\section{2}

A pesquisa faz parte de um estudo mais amplo promovido pela UFG e realizado pelo Núcleo de Estudos sobre Criminalidade e Violência - NECRIVI/ FCS - intitulado Violências, conflitos e crimes: subsidios para a formulação da política de segurança da UFG, 2014/2015. Agradeço a Ricardo Barbosa de Lima, que coordenou a pesquisa survey, pela incorporação das questões relativas ao trabalho e afazeres domésticos, e a Guilherme Borges da Silva, pela tabulação dos dados. 
reflete a realidade do ensino superior brasileiro, em que as mulheres ultrapassaram os homens tanto em número de matrículas como em concluintes de cursos de graduação. Segundo o Censo de Educação Superior realizado pelo Inep, as mulheres representavam 55,5\% dos matriculados e 59,6\% dos concluintes de 2012 (BRASIL, 2014).

O pertencimento étnico-racial é outra importante condição para o melhor entendimento da categoria de jovens alunos e alunas universitários. Quase metade dos/as estudantes classificou sua cor/raça como branca (49,1\%), 36,6\% declararam-na como parda e cerca de 10\% como preta. As demais formas de identificação foram: 1,6\% amarela, 0,2\% indígena e $0,9 \%$ outra resposta. Não houve diferenças significativas de percentual de cor/raça entre as alunas e os alunos.

\section{GRÁFICO 1}

DISTRIBUIÇÃO DE ESTUDANTES SEGUNDO COR/RAÇA (\%)

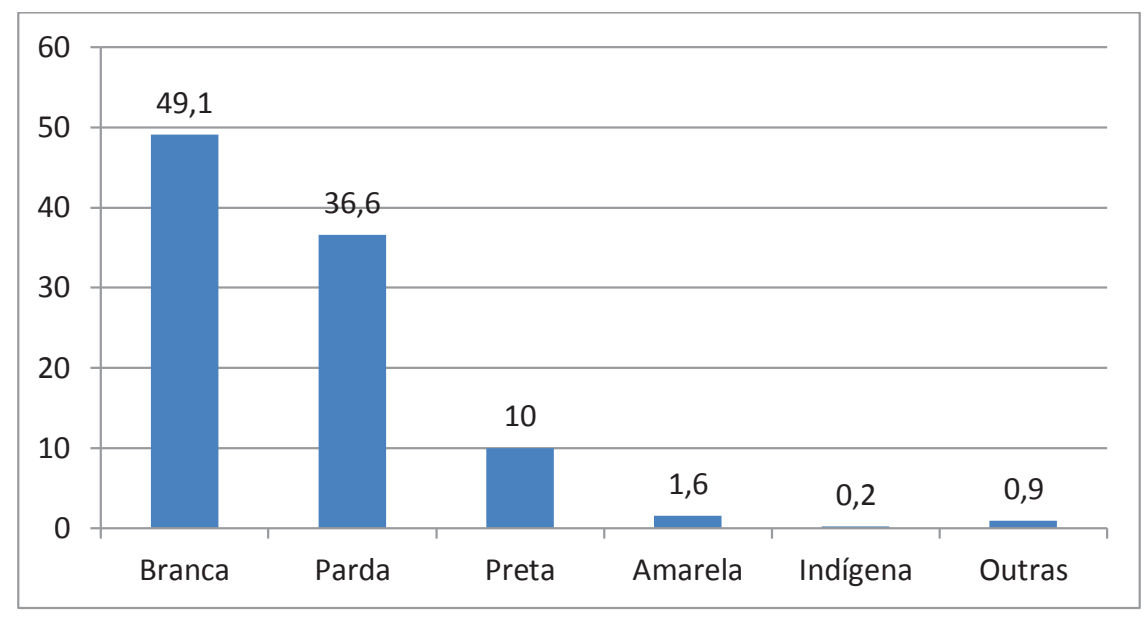

Fonte: Elaborado pela autora com base na pesquisa NECRIVI/UFG, 2014-2015.

No Brasil, 53\% das pessoas se declararam pretas e pardas, segundo a Pesquisa Nacional por Amostra de Domicílios - Pnad - de 2013 (INSTITUTO BRASILEIRO DE GEOGRAFIA E ESTATÍSTICA - IBGE, 2015), o que resulta em um percentual um pouco maior de negros do que o encontrado na amostra de estudantes da UFG. Segundo Lima e Prates (2015), a taxa de escolarização entre brancos e negros ainda é desigual no ensino médio, o que se intensifica no ensino superior. O estudo observa que a intersecção entre os indicadores de cor e renda aponta para uma desigualdade mais acentuada em que o negro pobre apresenta maior dificuldade do que o branco pobre para atingir maior escolaridade (LIMA; PRATES, 2015). No entanto, o número de estudantes negros/as nas instituições de ensino superior está em plena expansão. Embora ainda haja uma maioria de pessoas identificadas como brancas, o percentual de negras/os e indígenas no ensino superior tem se ampliado nos últimos anos devido a uma maior democratização do acesso e de políticas públicas, como as ações afirmativas que promovem maior equidade para 
inclusão de grupos e populações historicamente excluídos desse nível de ensino (FERES JR.; DAFLON, 2014).

No que diz respeito à idade dos alunos e alunas da universidade, a grande maioria é composta por jovens de até 26 anos (85,6\%), sendo que quase $40 \%$ estão na faixa etária entre 15 e 20 anos. Assim, não é muito expressivo o percentual de estudantes que está acima da faixa considerada adequada para frequentar o ensino superior. Como forma de contextualizar o que demograficamente pode ser considerada a população jovem, as pessoas na faixa etária entre 15 e 24 anos correspondem a $16,6 \%$ da população brasileira em $2013^{3}$ (IBGE, 2015). Isso indica um decréscimo na proporção de jovens que, em 1996, por exemplo, representavam 19,8\% do total da população (IBGE, 1999). Esse dado está relacionado à queda da taxa de natalidade e aumento da expectativa de vida e, consequentemente, ao maior envelhecimento populacional. Desde meados dos anos 1980 o Brasil não é mais considerado um país de população jovem e, com o crescimento acelerado da categoria dos idosos, esses estão próximos de ultrapassar o número de jovens no país (KUCHEMANN, 2012). É importante destacar, ainda, o alto índice de mortalidade de jovens, sobretudo por morte violenta. Conforme dados do Mapa da Violência, as mortes violentas passaram de 16.487 em 1980 para 22.041 em 2013. Aos 18 anos, as causas externas (homicídios, suicídios e acidentes de automóveis) representam 77,5\% das mortes de jovens no Brasil (WAISELFISZ, 2015).

Outro fator que permite melhor compreensão da população estudada é a escolaridade da família. A maior parte dos/as estudantes pesquisados/as vem de famílias cuja pessoa de referência ${ }^{4}$ possui ensino médio ou superior completo. Para 42,5\% dos/as estudantes, a pessoa de referência da família possui ensino médio completo ou superior incompleto, enquanto para 32,1\% essa pessoa já concluiu o ensino superior. Ao considerarmos os indicadores de cor/raça, verifica-se que 37,5\% dos/as estudantes declarados/as brancos/as vêm de famílias com escolaridade entre médio completo e superior incompleto e quase $40 \%$ de famílias com nível superior. Para estudantes negros/as (abrangendo pretos e pardos), 48,4\% são de famílias com ensino médio ou superior incompleto e somente $24,6 \%$ apresentam ensino superior completo. ${ }^{5}$ Traçando um paralelo com os dados do país, apenas 13,9\% dos ocupados completaram o nível superior de escolaridade, segundo a Pnad de 2013 (IBGE, 2015). Observa-se, portanto, que os/as estudantes analisados/as pertencem a famílias com escolaridade mais elevada que a média dos ocupados/as brasileiros/as. Essa afirmativa sustenta-se face às visíveis desigualdades encontradas entre as famílias de estudantes negros/as e brancos/as. Embora o percentual de entrevistados/as negros/as de família com ensino superior completo seja bem inferior ao de estudantes brancos/as, ainda assim é maior do que a média brasileira.

3

Não há consenso quanto a um critério etário delimitado para definir juventude (GROPPO, 2000), mas, nesses estudos, O IBGE está circunscrevendo a população jovem na faixa etária entre 15 e 24 anos (IBGE, 1999; IBGE, 2015). 4 Segundo o IBGE, a pessoa de referência é a pessoa responsável pela unidade domiciliar (ou pela família) ou assim considerada pelos demais membros. 5

As demais respostas em termos das classificações de cor/raça (amarela, indígena e outras) não estão em análise por serem estatisticamente pouco significativas, conforme visto acima. 


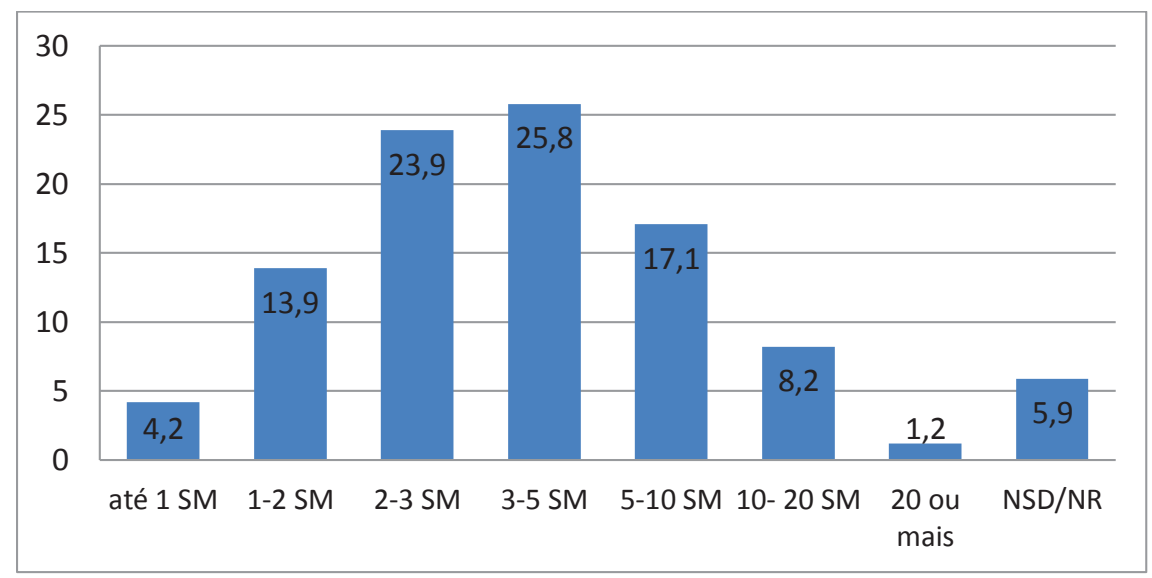

NR = nenhuma das respostas; NSD = não souberam dizer; $\mathrm{SM}$ = salário mínimo. Fonte: Elaborado pela autora com base na pesquisa NECRIVI/UFG, 2014-2015.

Ainda, em se tratando de caracterizar a família dos/as alunos e alunas pesquisados/as, é preciso considerar sua posição socioeconômica. Os/as estudantes em questão apresentam renda familiar dispersa entre média e baixa: $25,8 \%$ estão na faixa de três a cinco salários mínimos, $23,9 \%$ entre dois e três salários e 18,1\% têm renda familiar de menos de dois salários. No entanto, os resultados apresentam variações significativas na interseção dos indicadores de renda e cor/raça. Entre os/as que se identificam como brancos/as, 13,1\% têm renda familiar de até dois salários mínimos e 14,7\% de mais de dez salários mínimos. Em contrapartida, entre os/as declarados/as negros/as, 23,4\% têm renda familiar de até dois salários mínimos e apenas 4,4\% atingem a faixa de mais de dez salários. De acordo com a Pnad de 2013, a média de rendimentos dos domicílios brasileiros desse ano foi de $\mathrm{R} \$ 2.933,00$, o que daria pouco mais de quatro salários mínimos se considerado o valor do salário mínimo do período (IBGE, 2015).

Contudo, o jovem que entra para a universidade destaca-se pela perspectiva de construção de sua autonomia e isso implica também em buscar sua própria renda, em especial para aqueles cuja família não possui condições de arcar com suas despesas. Assim, um indicador fundamental nessa análise é distinguir entre estudantes que estão ou não inseridos no mercado de trabalho. Do total de estudantes universitários pesquisados, 32,3\% trabalham de forma remunerada. Esse percentual é mais que o dobro do número de brasileiros/as de 18 a 24 anos que aliam trabalho e estudo, de acordo com a Síntese de Indicadores Sociais de 2012 (IBGE, 2013). Segundo esses dados, enquanto 14,8\% das pessoas de 18 a 24 anos trabalham e estudam, $14,5 \%$ só estudam, 47,3\% só trabalham e $23,4 \%$ não estudam nem trabalham. Entre os jovens do último grupo, há maioria de mulheres (68\%), fato que está fortemente 
relacionado com a maternidade e a dificuldade que muitas enfrentam de conciliá-la com o estudo e a participação em atividades remuneradas (IBGE, 2013).

\section{ARTICULAÇÃO ENTRE ESTUDO, TRABALHO E FAMÍLIA}

Considerando a relação entre trabalho e gênero, é possível perceber algumas diferenças entre as alunas e os alunos na pesquisa. Em primeiro lugar, mais alunos do que alunas acumulam o estudo com trabalho remunerado. Enquanto 38\% dos estudantes são trabalhadores, 28\% das estudantes estão na mesma categoria. Em segundo lugar, há diferenças consideráveis na contribuição de estudantes para a renda familiar segundo o sexo. Entre os alunos ocupados, $48,3 \%$ participam em menos de $40 \%$ do total da renda familiar, $13,5 \%$ contribuem na faixa de $40 \%$ a $60 \%$ do total e $30,3 \%$ participam com mais de $60 \%$ da renda (quase $8 \%$ não souberam responder qual sua contribuição na renda). Em contrapartida, a maioria das alunas que trabalha tem baixa participação na renda familiar (63\%), 21\% estão na faixa intermediária e apenas 7,4\% na faixa de maior participação na renda da família (8,6\% não souberam responder).

\section{GRÁFICO 3}

PERCENTUAL DE PARTICIPAÇÃO DE ESTUDANTES NA RENDA FAMILIAR

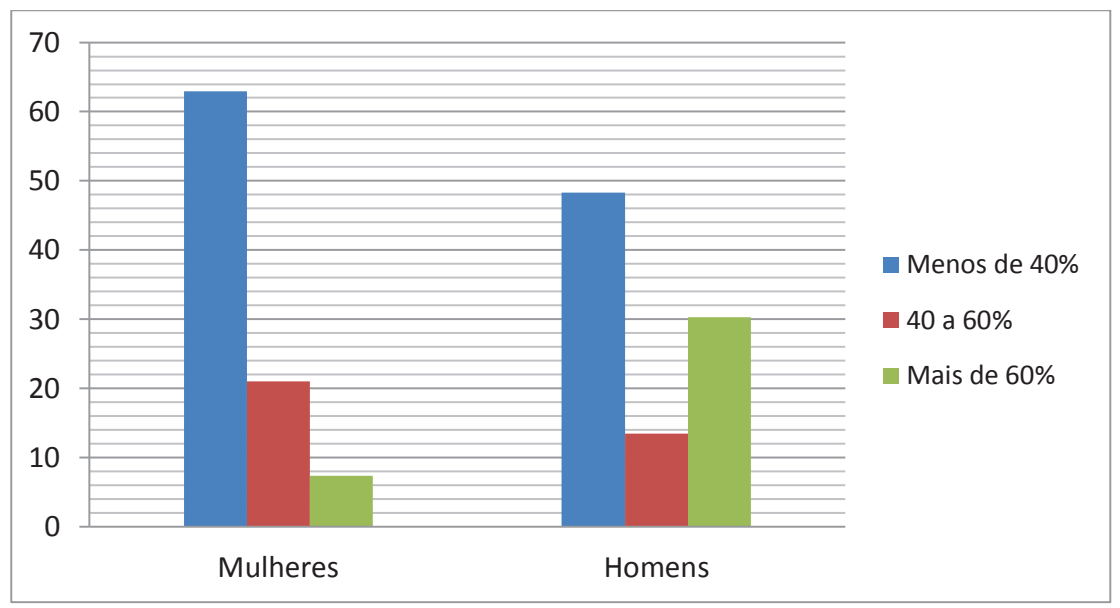

Fonte: Elaborado pela autora com base na pesquisa NECRIVI/UFG, 2014-2015.

Esses resultados refletem a menor remuneração feminina no mercado de trabalho ${ }^{6}$ (ARAÚJO; LOMBARDI, 2013), além da maior pressão sofrida pelos homens para trabalhar e assumir a responsabilidade pelo sustento familiar. De modo geral, os homens começam a trabalhar mais cedo do que as mulheres, o que pode ser observado nos dados da Pnad de 2013, segundo os quais 64,6\% das crianças e adolescentes (entre 5 e 17 anos) que trabalham são do sexo masculino (IBGE, 2015). Nesse sentido, os estereótipos de gênero contribuem para que os jovens de sexo masculino abandonem os estudos mais cedo para trabalhar, enquanto as mulheres ocupadas brasileiras recebem $73,5 \%$ do total do rendimento do trabalho dos homens (IBGE, 2015). 
as jovens deixam de estudar (em menor proporção) principalmente por razões relacionadas à maternidade e ao trabalho reprodutivo. É preciso ressaltar, entretanto, que, embora a inserção no trabalho prejudique os meninos mais intensamente (principalmente os negros e mais pobres), esse fator não é suficiente para explicar a diferença entre os sexos na defasagem escolar (ARTES; CARVALHO, 2010). Outros elementos, como a construção das feminilidades e masculinidades e a diferença na expectativa escolar das famílias para meninas e meninos, são apontados como pistas para compreender o maior êxito das mulheres no processo de escolarização (SENKEVICS; CARVALHO, 2015).

O tempo de trabalho configura-se central para a análise da articulação que os/as estudantes realizam entre a atividade remunerada, a formação educacional e os cuidados com a casa e família. Comparando com a jornada média dos/as brasileiros/as e, mais especificamente, das demais categorias da comunidade universitária analisada (a maioria apresenta jornada acima de 40 horas semanais), o tempo de trabalho desses/as estudantes é consideravelmente menor.

Para os alunos do sexo masculino com trabalho remunerado, $56,2 \%$ afirmam que dedicam menos de 40 horas por semana ao trabalho, 24,7\% dedicam 40 horas e 16,9\% dedicam mais de 40 horas. Enquanto isso, para as mulheres, as jornadas são ainda mais reduzidas: 75,3\% trabalham menos de 40 horas por semana, 14,8\% trabalham 40 horas e apenas 9,9\% trabalham mais de 40 horas. Em termos comparativos, segundo a Pnad de 2012, a jornada de trabalho média para os ocupados do sexo masculino é de 42,1 horas semanais e, para as do sexo feminino, é de 36,1 horas (IBGE, 2013).

\section{GRÁFICO 4}

DISTRIBUIÇÃO DA JORNADA DE TRABALHO REMUNERADO ENTRE ESTUDANTES

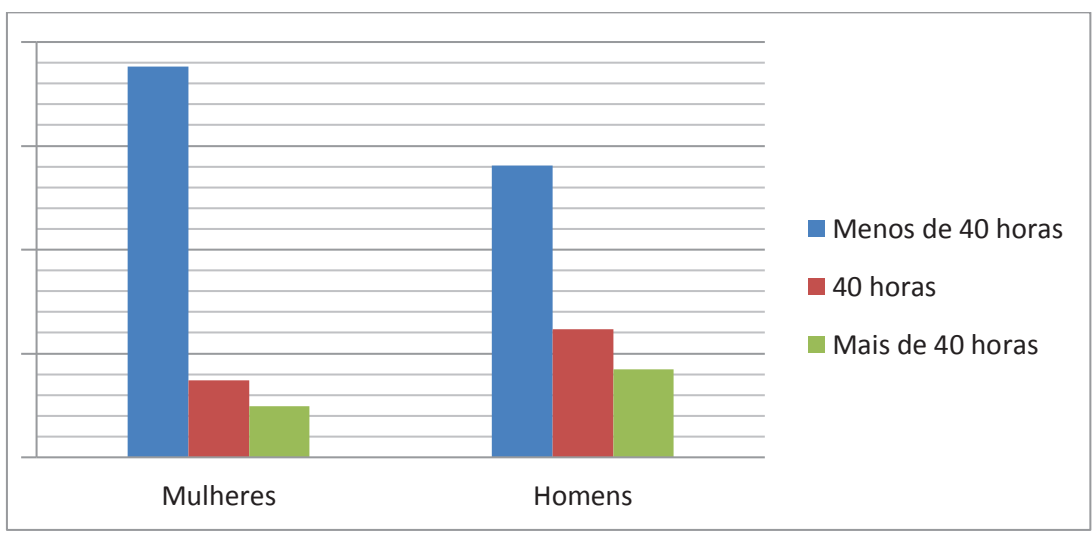

Fonte: Elaborado pela autora com base na Pesquisa NECRIVI/UFG, 2014-2015.

O índice de tempo total de trabalho expressa, de forma mais adequada, a quantidade de tempo investido por mulheres e homens no 
trabalho, somando trabalho remunerado e não remunerado. No Brasil, 88\% das mulheres ocupadas de 16 anos ou mais de idade realizam afazeres domésticos, enquanto, entre os homens, esse percentual cai para 46\%, segundo dados da Síntese de Indicadores Sociais de 2013 (IBGE, 2015). As mulheres têm jornada média em afazeres domésticos mais que o dobro da observada para os homens (20,6 horas/semana). Somando o tempo de trabalho remunerado com o tempo de trabalho doméstico, tem-se uma jornada feminina semanal total de 56,4 horas, superior em quase cinco horas à jornada masculina. Verifica-se, assim, que as mulheres trabalham mais, mesmo que a média de jornada masculina no trabalho produtivo seja maior.

As desigualdades de gênero no mundo do trabalho e na sociedade podem ser desveladas por meio da perspectiva das relações de gênero e da divisão sexual do trabalho (KERGOAT, 2009). Para a autora, além da destinação prioritária de mulheres para a esfera reprodutiva e de homens para a produtiva, a divisão sexual do trabalho estrutura-se a partir dos princípios de separação (atividades de mulheres distintas de atividades de homens) e de hierarquização (trabalho de homens vale mais que o trabalho de mulheres). A partir dessa concepção, a articulação entre trabalho produtivo (remunerado) e reprodutivo (ou doméstico) torna-se fundamental para compreender as relações de trabalho como um todo. Como o trabalho reprodutivo não remunerado é realizado majoritariamente pelas mulheres, é preciso compreender as implicações dessa realidade nas possibilidades e práticas sociais de homens e mulheres.

As esferas de produção e de reprodução devem ser pensadas de forma articulada, uma vez que o tempo do trabalho remunerado é condicionado pelo tempo do trabalho doméstico. Com a atribuição da responsabilidade principal pelo trabalho reprodutivo às mulheres, seu tempo precisa multiplicar-se entre família e ocupação (HIRATA; ZARIFIAN, 2009), questão que geralmente não se coloca para os homens que, mesmo diante do crescimento da participação feminina no mercado de trabalho, ainda apresentam resistência à divisão do trabalho doméstico. Quando ocorre, a participação masculina enquadra-se como "ajuda” e não como "obrigação" ou partilha de responsabilidades (BILAC, 2014; BRUSCHINI; RICOLDI, 2012).

Pensando a população universitária como um todo, 12,3\% dos homens afirmaram que não despendem nenhuma hora por semana para os afazeres domésticos. ${ }^{7} \mathrm{O}$ índice de mulheres que não têm participação nenhuma nos afazeres domésticos é de menos da metade desse valor. Em geral, os homens concentram-se entre os que gastam pouco ou nenhum tempo para os afazeres domésticos e as mulheres estão mais presentes nas jornadas mais longas. Assim, na categoria de pessoas que dedicam mais de dez horas semanais ao trabalho doméstico, há 24,5\% de mulheres, mas somente 6,8\% dos homens.

7

Na pesquisa, utilizou-se a definição de afazeres domésticos do IBGE, que compreende a realização, no domicílio de residência, de tarefas de: a) Arrumar ou limpar toda ou parte da moradia; b) Cozinhar ou preparar alimentos, passar roupa, lavar roupa ou louça, utilizando, ou não, aparelhos eletrodomésticos para executar essas tarefas para si ou para outro(s) morador(es); c) Orientar ou dirigir trabalhadores domésticos na execução das tarefas domésticas; d) Cuidar de filhos ou menores moradores; ou e) Limpar o quintal ou terreno que circunda a residência. 
Apesar de manter o padrão geral de mais longas horas de trabalho doméstico para mulheres, o tempo gasto com afazeres domésticos das estudantes foi bem menor que das mulheres das demais categorias da comunidade universitária: 6,2\% das alunas não despendem nenhuma hora de seu tempo para as tarefas domésticas, $42,1 \%$ despendem entre uma a cinco horas, $26,4 \%$ entre seis e dez horas e $19,9 \%$ gastam mais de dez horas para o trabalho doméstico (enquanto 5,5\% não souberam responder). Entre os alunos, 12,8\% não têm nenhuma participação, 51,1\% dedicam entre uma a cinco horas semanais, 21,3\% dedicam de seis a dez horas e somente $6 \%$ usam mais de dez horas semanais para os afazeres domésticos (8,9\% não souberam responder a essa questão).
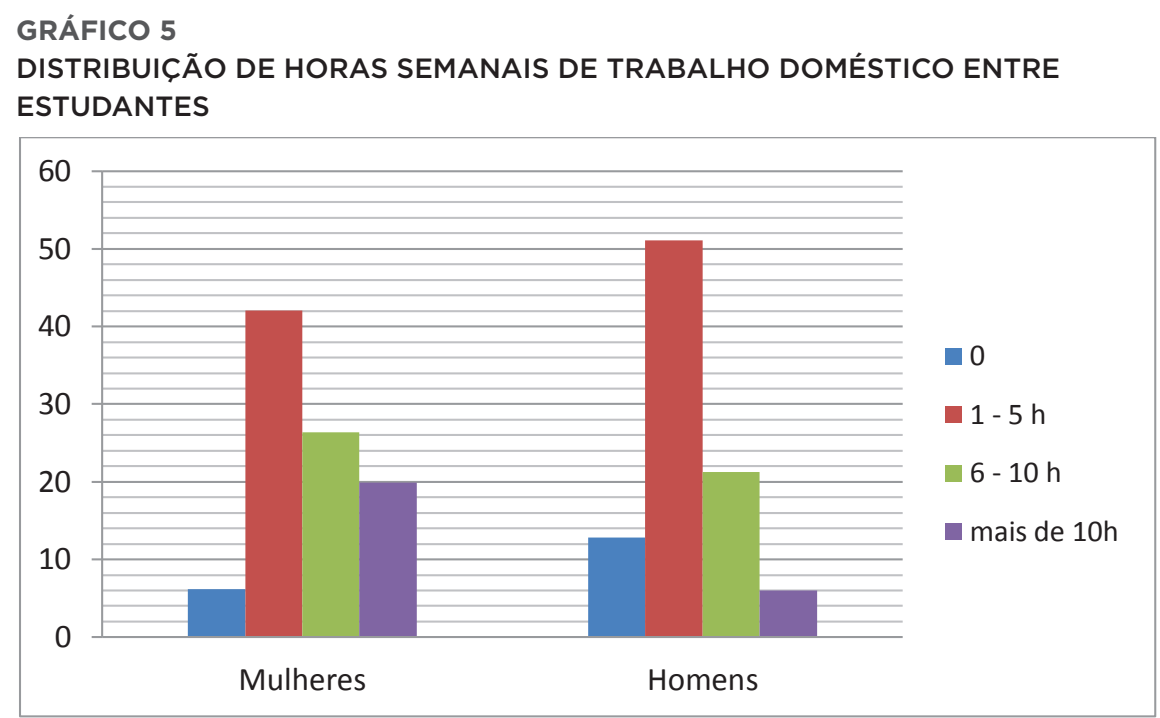

Fonte: Elaborado pela autora com base na pesquisa NECRIVI/UFG, 2014-2015.

Para compreender o trabalho reprodutivo, além de mensurar o tempo dedicado às atividades domésticas, é preciso analisar quem assume a responsabilidade principal por essas tarefas. Considerando a resposta de todas as categorias da população universitária entrevistada segundo o sexo, 43,2\% das mulheres consideram-se as principais responsáveis pelos afazeres domésticos. Além de os respondentes homens representarem metade do percentual das mulheres que se consideram responsáveis pelas atividades domésticas, a presença masculina em geral é muito baixa. Ao contrário da mãe, grande protagonista das atividades domésticas, o pai tem participação insignificante ou nula, como responsável pelos afazeres tanto de entrevistadas como de entrevistados. 


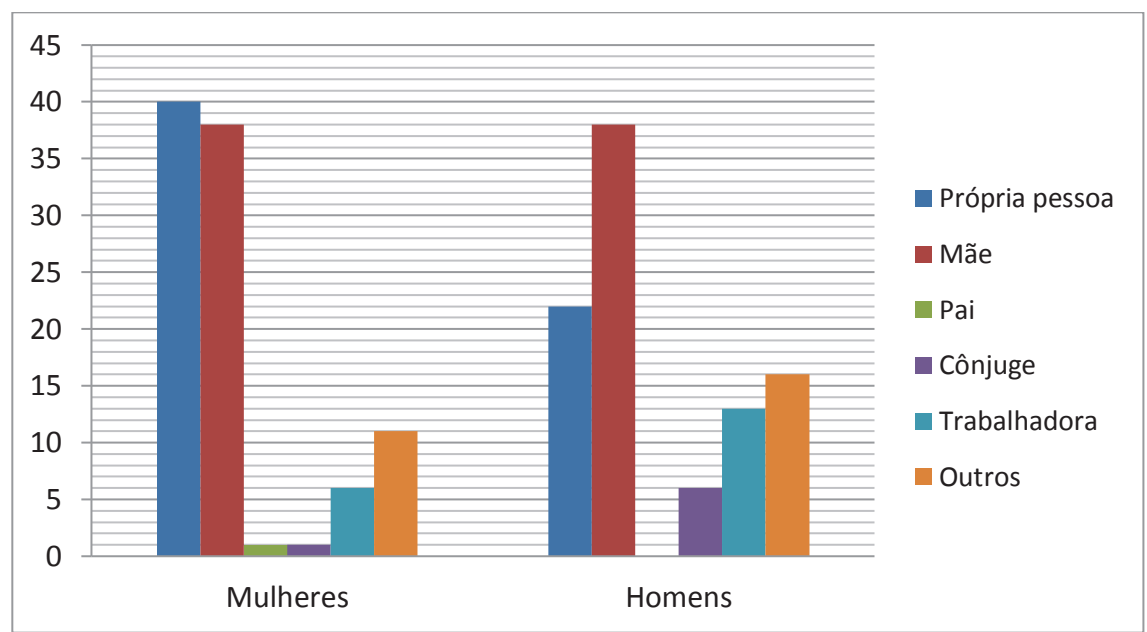

Fonte: Elaborado pela autora com base na pesquisa NECRIVI/UFG, 2014-2015.

Entre as estudantes universitárias, 40,4\% assumem ser as principais responsáveis pelo trabalho doméstico, para 37,7\% as responsáveis são as mães, para $11 \%$ são outras pessoas e para 6,2\% são as trabalhadoras domésticas. Em contrapartida, os estudantes do sexo masculino deixam a responsabilidade principal para a mãe em 38,3\% dos casos, $21,7 \%$ afirmam ser os responsáveis, para 15,7\%, são outras pessoas, para 13,2\%, são as trabalhadoras domésticas e, para 6,4\%, as cônjuges.

Analisando a interseção entre gênero e raça, há diferenças consideráveis nas respostas entre os estudantes brancos e negros do sexo masculino. Apenas 18,3\% dos declarados brancos são os responsáveis pelas tarefas domésticas, percentual que sobe para 25,7\% entre os negros. Outro dado importante é que enquanto 19,2\% dos brancos transferem o trabalho para um/a trabalhador/a doméstico/a, apenas 6,4\% dos negros fazem o mesmo. Esses resultados são forte evidência da importância de pensar as imbricações entre as desigualdades de gênero, raça e classe e concebê-las como relações sociais consubstanciais, produzindo-se e coproduzindo-se mutuamente (HIRATA, 2014; KERGOAT, 2010). No entanto, é preciso reconhecer que as relações de gênero ainda têm papel preponderante quando o foco está no trabalho reprodutivo. Mesmo que os jovens negros assumam, em maior número, os afazeres domésticos em comparação aos brancos, o percentual de estudantes mulheres que se atribuem o papel principal nos trabalhos de casa ainda é bem maior (com pouca diferenciação entre elas em termos de cor/raça).

Enquanto os homens de todas as outras categorias (docentes, técnicos e terceirizados) têm em comum a resposta de que em cerca de $44 \%$ dos casos são as cônjuges as protagonistas do trabalho doméstico, para os estudantes é a mãe quem ocupa o posto principal em quase 40\% das 
respostas. Percebe-se, portanto, que mesmo entre estudantes universitários, jovens e com acesso ao ensino superior, a divisão do trabalho doméstico segue os moldes tradicionais das normas de gênero em que as mulheres são as grandes responsáveis pelo trabalho doméstico.

\section{CONSIDERAÇÕES FINAIS}

A representação da mulher, destinada prioritariamente ao trabalho reprodutivo, subsiste no imaginário e na prática social da população analisada, levando em consideração o grande número de mulheres que é a principal responsável pelos afazeres domésticos. Algumas pesquisas apontam indícios de que os homens mais jovens participam mais do trabalho doméstico do que os das gerações anteriores, embora as companheiras permaneçam como as principais realizadoras (ÁVILA; FERREIRA, 2014; BRUSCHINI; RICOLDI, 2012). No caso dos estudantes universitários, é provável que grande parte ainda esteja morando com familiares na condição de filhos, o que de certa forma relativiza a questão da responsabilidade pelos afazeres da casa. ${ }^{8}$ De todo modo, não é possível constatar um rompimento com a concepção da divisão sexual do trabalho e consequente apropriação do trabalho gratuito das mulheres, o que acarreta sobrecarga feminina e concorre para o acirramento das desigualdades de gênero no mercado de trabalho. Embora haja alguns sinais de mudança, a concepção de Mannheim da juventude como força transformadora da sociedade não pode ser generalizada no caso das desigualdades de gênero que atravessam a sociedade. Entretanto, não se pode esquecer que o autor aponta que as novas gerações constituem um agente dinamizador "em potencial”, mas que poderia ser também uma força de conservação (GROPPO, 2000; MANNHEIM, 1980).

O crescimento da inserção de mulheres no trabalho remunerado não foi acompanhado por maior participação do homem na partilha do trabalho doméstico, nem por políticas públicas ou mudanças na organização produtiva que permitissem a conciliação entre estudo, trabalho e vida privada e familiar. Assim, o modelo de articulação entre trabalho e família não sofre grandes modificações: quando não é a responsável pelo trabalho doméstico, a mulher delega a tarefa a outra mulher, familiar ou contratada.

No caso das estudantes, mesmo que de ensino superior, o trabalho reprodutivo é visto como responsabilidade da própria estudante ou da mãe, ao contrário dos universitários do sexo masculino, que delegam essa responsabilidade majoritariamente para a mãe. Buscando maior qualificação e formação educacional, além de assumir a responsabilidade pelo espaço reprodutivo, muitas vezes aliada à inserção no trabalho produtivo, as jovens estudantes buscam articular tempos e espaços em uma sociedade que não consolidou a socialização da reprodução 
nem a partilha igualitária de responsabilidades na produção da vida. Resta saber se as novas gerações de jovens que irromperam na chamada "primavera feminista", ${ }^{9}$ protagonizando movimentos de resistência e ocupando o espaço público, deixarão um campo fértil para mudanças, desafiando as hegemonias de gênero também na esfera do privado.

\section{REFERÊNCIAS}

ABRAMO, Helena Wendel. Cenas juvenis: punks e darks no espetáculo urbano. São Paulo, SP: Scritta; Anpocs, 1994.

ARAÚJO, Ângela; LOMBARDI, Maria Rosa. Trabalho informal, gênero e raça no Brasil do início do século XXI. Cadernos de Pesquisa, São Paulo, v. 43, n. 149, p. 452-477, 2013.

ARTES, Amélia Cristina Abreu; CARVALHO, Marília Pinto de. O trabalho como fator determinante da defasagem escolar dos meninos no Brasil: mito ou realidade? Cadernos Pagu, Campinas, n. 34, p. 41-74, 2010.

ÁVILA, Maria Betânia; FERREIRA, Verônica. Trabalho remunerado e trabalho doméstico no cotidiano das mulheres. Recife: SOS Corpo; São Paulo: Instituto Patrícia Galvão, 2014.

BEZERRA, Heloísa Dias et al. Juventude e política: entre a vontade geral e o abandono do Estado. In: BEZERRA, Heloísa Dias; OLIVEIRA, Sandra (Org.). Juventude no século XXI: dilemas e perspectivas. Goiânia, GO: Cânone, 2013. p. 95-132.

BILAC, Elisabete Dória. Trabalho e família: articulações possíveis. Tempo Social, São Paulo, v. 26, n. 1, p. 129-145, 2014.

BRASIL. Instituto Nacional de Estudos e Pesquisas Educacionais "Anísio Teixeira” - Inep. Censo da educação superior 2012: resumo técnico. Brasília, DF: Inep, 2014.

BRUSCHINI, Cristina; RICOLDI, Arlene. Revendo estereótipos: o papel dos homens no trabalho doméstico. Revista Estudos Feministas, Florianópolis, v. 20, n. 1, p. 259-287, 2012.

CARMO, Paulo Sérgio. Juventude no singular e no plural. Cadernos Adenauer, Rio de Janeiro, ano II, n. 6, p. 9-29, 2001.

DUFFY, Mignon. Doing the dirty work: gender, race, and reproductive labor in historical perspective. Gender \& Society, Thousand Oaks, v. 21, n. 3, p. 313-336, 2007.

FERES JÚNIOR, João; DAFLON, Verônica. Políticas de igualdade racial no ensino superior. Cadernos do Desenvolvimento Fluminense, Rio de Janeiro, n. 5, p. 31-43, jul. 2014.

FOUGEYROLLAS-SCHWEBEL, Dominique. Trabalho doméstico. In: HIRATA, Helena et al. (Org.). Dicionário crítico do feminismo. São Paulo, SP: Unesp, 2009. p. 256-262.

FRAGA, Paulo Cesar Pontes; IULIANELLI, Jorge Atílio Silva (Org.). Jovens em tempo real. Rio de Janeiro: DP\&A, 2003.

GROPPO, Luís Antonio. Juventude: ensaios sobre a sociologia e história das juventudes modernas. Rio de Janeiro: Difel, 2000.

HIRATA, Helena. Gênero, classe e raça: interseccionalidade e consubstancialidade das relações sociais. Tempo Social, São Paulo, v. 26, n. 1, p. 61-73, jun. 2014.

HIRATA, Helena; ZARIFIAN, Philippe. Trabalho. In: HIRATA, Helena et al. (Org.). Dicionário crítico do feminismo. São Paulo, SP: Unesp, 2009. p. 251-256.

INSTITUTO BRASILEIRO DE GEOGRAFIA E ESTATÍSTICA. População jovem no Brasil. Rio de Janeiro: IBGE, 1999. (Estudos e pesquisas. Informação demográfica e socioeconômica, n. 3).

INSTITUTO BRASILEIRO DE GEOGRAFIA E ESTATÍSTICA. Pesquisa nacional por amostra de domicílios: síntese de indicadores 2012. Rio de Janeiro: IBGE, 2013.

A "primavera feminista" foi assim denominada pela mídia a partir de uma série de atos nas ruas e nas redes sociais que eclodiram na primavera de 2015 , nos quais milhares de mulheres de todo o país manifestaram-se contra uma pauta de retrocessos aos seus direitos, abrangendo também o enfrentamento às várias formas de violência contra a mulher e o protagonismo feminino nas resistências de estudantes e na luta pela democracia. 
INSTITUTO BRASILEIRO DE GEOGRAFIA E ESTATÍSTICA. Pesquisa nacional por amostra de domicílios: síntese de indicadores 2013. 2. ed. Rio de Janeiro: IBGE, 2015.

KERGOAT, Danièle. Divisão sexual do trabalho e relações sociais de sexo. In: HIRATA, Helena et al. (Org.). Dicionário crítico do feminismo. São Paulo, SP: Unesp, 2009. p. 67-75.

KERGOAT, Danièle. Dinâmica e consubstancialidade das relações sociais. Novos estudos Cebrap, n. 86, p. 93-103, mar. 2010.

KUCHEMANN, Berlindes Astrid. Envelhecimento populacional, cuidado e cidadania: velhos dilemas e novos desafios. Sociedade e Estado, Brasília, v. 27, n. 1, p. 165-180, jan./abr. 2012.

LIMA, Márcia; PRATES, Ian. Desigualdades raciais no Brasil: um desafio persistente. In: ARRETCHE, Marta (Org.). Trajetórias das desigualdades: como o Brasil mudou nos últimos cinquenta anos. São Paulo, SP: Editora Unesp; CEM, 2015. p. 163-189.

MANNHEIM, Karl. O problema da juventude na sociedade moderna. In: MANNHEIM, Karl. Diagnóstico de nosso tempo. Rio de Janeiro: Zahar, 1980. p. 47-72.

SENKEVICS, Adriano Souza; CARVALHO, Marília Pinto de. Casa, rua, escola: gênero e escolarização em setores populares urbanos. Cadernos de Pesquisa, São Paulo, v. 45, n. 158, p. 944-968, 2015.

TAVARES, Breitner. Na quebrada, a parceria é mais forte: jovens, vínculos afetivos e reconhecimento na periferia. São Paulo, SP: Annablume, 2012.

WAISELFISZ, Júlio Jacobo. Mapa da violência 2015: adolescentes de 16 e 17 anos do Brasil. Rio de Janeiro: Flacso, 2015.

WELLER, Wivian. A atualidade do conceito de gerações de Karl Mannheim. Sociedade e Estado, Brasília, v. 25, n. 2, p. 204-225, maio/ago. 2010.

WELLER, Wivian. Minha voz é tudo o que tenho: manifestações juvenis em Berlim e São Paulo. Belo Horizonte: Humanitas, 2011.

TANIA LUDMILA DIAS TOSTA

Professora da Universidade Federal de Goiás - UFG -, Goiânia, Goiás, Brasil tantosta@hotmail.com 